\title{
SYNTHESIS AND NMR CHARACTERIZATION OF ALIPHATIC-AROMATIC COPOLYESTERS BY REACTION OF POLY(ETHYLENE TEREPHTHALATE) POST-CONSUMER AND POLY(ETHYLENE ADIPATE)
}

\author{
Alessandra F. Baldissera, Carlos E. S. Valério, Nara. R. de S. Basso, Fernando Guaragna e Sandra Einloft* \\ Faculdade de Química, Pontifícia Universidade Católica do Rio Grande do Sul, Av. Ipiranga, 6681, Prédio 12 A, \\ 90619-900 Porto Alegre - RS
}

Martine Tessier e Alain Fradet

Université Pierre et Marie Curie, U.M.R. 7610 Chimie des Polymères, Laboratoire de Synthèse Macromoléculaire, Paris - França

Recebido em 28/11/03; aceito em 4/10/04; publicado na web em 28/1/05

\begin{abstract}
An aliphatic-aromatic copolyester of poly(ethylene terephthalate), PET, and poly(ethylene adipate), PEA, PET-co-PEA, was synthesized by the high temperature melt reaction of post-consumer PET and PEA. As observed by NMR spectroscopy, the reaction yielded random copolyesters in a few minutes through ester-interchange reactions, even without added catalyst. The copolyesters obtained in the presence of a catalyst presented higher intrinsic viscosity than that obtained without the addition of catalyst, due to simultaneous polycondensation and ester-interchange reactions. The structure of the aliphatic-aromatic copolyesters obtained in different PET/PEA ratio is random as observed by NMR analysis.
\end{abstract}

Keywords: aliphatic-aromatic copolyesters; polyethylene terephthalate; chemical recycling.

\section{INTRODUCTION}

Poly(ethylene terephthalate) (PET) is a polyester widely used in many everyday applications, mainly due to its low production cost, good mechanical properties and recyclability. PET is commonly encountered in plastic bottles for soft drink and in films which are used for food and liquid packaging, magnetic tapes and novelty balloons, among others applications ${ }^{1,2}$. PET is a nonbiodegradable polymer, resistant to hydrolysis in mild $\mathrm{pH}$ conditions, innocuous to human body, it is looked as a noxious material due to the great volume in waste streams and high resistance to atmospheric and biological agents ${ }^{2,3}$.

One possible solution for this problem would be the development of new biodegradable polymers. The commercially available biodegradable polymers are mostly aliphatic polyester, as for example, poly(3-hydroxyalkanoate)s, poly(e-caprolactone) and so on, this polyesters including their copolyester can cover a wide range of properties needed for most purposes ${ }^{4}$. The development of new types of biodegradable polymers with different properties of conventional aliphatic polyesters is highly desirable due to the great number of specific requirements for polymeric materials ${ }^{4}$.

In this way, the modification of non-biodegradable polymers with biodegradable polymers, for example, incorporating aliphatic units in the PET chain either by polymer-polymer transesterification or by copolymerization of the commonomers ${ }^{2}$, resulting in aliphatic/ aromatic copolyester is an interesting way to develop new biodegradable copolymers. The reactive blending of the well knows homopolyesters is an inexpensive method to obtain new aliphatic/ aromatic copolyesters with intermediates properties ${ }^{5}$.

The modification of PET structure with $10 \%$ of poly(ethylene adipate) PEA make it biodegradable in typical environmental conditions in the presence of water ${ }^{6}$. The hydrolysable poly(ethylene terephthalate- co ethylene adipate) shows a loss of weight for samples exposed to $\mathrm{PH} 7,0$ water at $80{ }^{\circ} \mathrm{C}$, whereas no change was

*e-mail: einloft@pucrs.br observed at room temperature. The copolyester was synthesized by simple ester exchange in the melt state of PET and PEA, stannous octoate was used for catalyzing the reaction which was performed at $265^{\circ} \mathrm{C}$ for $3 \mathrm{~h}$ under vaccuum ${ }^{6}$.

Copolyesters composed of aliphatic and aromatic units, such as, 1,2-ethanediol, 1,3-propanediol, 1,4-butanediol, sebacic acid, adipic acid and terephthalic acid combined in an appropriate ratio has proved to be biodegradable 7,8 .

The biodegradation behavior of copolyesters which contains aliphatic and aromatic subunits are dependent on composition, length and sequence distributions of aliphatic and aromatic units, cristalinity and melting temperature ${ }^{9,10}$.

It was shown that the biodegradability of chain segments consisting only of aromatic dicarboxylic acids, is particularly dependent on the number of repeating units ${ }^{8,9}$. It is necessary to known the degree of randomness of the copolyesters chains and the block length distribution to understand the biodegradation behavior of aliphatic/aromatic copolyesters ${ }^{10}$.

With the NMR spectroscopy the study of the molar fraction of the acids, the degree of randomness among other informations may be known. These data are very important to the understanding of the biodegradability properties of the aliphatic/aromatic copolyesters.

Recycling post-consumer PET into aliphatic-aromatic copolyesters exhibiting enhanced biodegradability, together with fair mechanical properties, is a potentially interesting approach: The use of ecofriendly, compostable plastics obtained from PET would be an elegant way of dealing with the problem of PET waste disposal.

In this work, we discuss the synthesis and characterization by NMR of aliphatic-aromatic copolyesters obtained by the high temperature melt reaction of post-consumer poly(ethylene terephthalate) PET with poly(ethylene adipate) PEA forming a copolyester PET-co-PEA, showing that it is possible to transform the post-consumer PET in another material by simple interchange ester-ester reaction. 


\section{EXPERIMENTAL PART}

\section{Materials and methods}

The catalyst utilized in all polymerization reactions was (Titanium butoxyde (IV)), obtained from Aldrich and used without further purification. Ethylene glycol from Merck and adipic acid from Vetec were used as received.

Synthesis of Poly(ethylene adipate)- (PEA)

PEA was prepared according the procedures described in the literature ${ }^{11}$. That is, by polycondensation reaction between the monomers ethylene glycol (EG) and adipic acid (AA) with an initial proportion of $(\mathrm{EG} / \mathrm{AA}=3 / 1)$, with elimination of water and $\mathrm{EG} .[\eta]$ $=0.0104 \mathrm{~mL} / \mathrm{mg}$

\section{Synthesis of copolyesters PET/PEA}

Samples of PET post-consumer $\left([\eta]=0.0736 \mathrm{~mL} / \mathrm{mg}, \mathrm{X}_{\mathrm{c}}=\right.$ $31 \%$ ) were cuted and dried at $100{ }^{\circ} \mathrm{C}$ for $1 \mathrm{~h}$ prior to use.

The copolymerization reactions were carried out in a $500 \mathrm{~mL}$ reactor system equipped with an air-driven stirrer, a thermocouple, a nitrogen inlet tube and vacuum system. The reactor is heated by means of an electrical mantle. The temperature is monitored via an Pt 100 thermocouple with a temperature controller. The mantle is connected to the automatic controller. The copolymers PET and PEA were synthesized in different ratios. In a typical reaction, PEA and PET (total weight $100 \mathrm{~g}$ ) are added, under $\mathrm{N}_{2}$, to the reactor and heated in approximately $15 \mathrm{~min}$ until $240^{\circ} \mathrm{C}$, then the catalyst $(0.146 \mathrm{mmol})$ (in the reactions with added catalyst) is added into the reaction flask. Then vacuum $(0.040 \mathrm{mmHg})$ is applied (at this step we start to count the reaction time), and the reaction is maintained for the desired reaction time. Then the reaction is stopped and the copolymer was put in another vessel at room temperature.

\section{NMR analysis}

Proton NMR spectra, of resultant copolyesters, were recorded on a Brucker - $300 \mathrm{MHz}$ spectrometer, chloroform + trifluoroacetic acid $(3 / 1 \mathrm{~mL} / \mathrm{mL})$ solution was used as the solvent. Chemical shifts were reported relative to the residual protons of chloroform-d (7.26 ppm). The NMR spectra were treated using MestRe-C 2.1.1 (Magnetic Resonance Companion, NMR Data Processing Program)

\section{Viscosity measurements}

The intrinsic viscosities $[\eta]$ of the copolymers were measured in chloroform solutions with an Ubbelohde viscometer thermostated at $25{ }^{\circ} \mathrm{C} \pm 0.05{ }^{\circ} \mathrm{C}$. The intrinsic viscosity of the PET sample was measured in dichloromethane + trichloroacetic acid $(4 / 1 \mathrm{~g} / \mathrm{g})$ solution in the same viscometer thermostated at $25{ }^{\circ} \mathrm{C} \pm 0.05{ }^{\circ} \mathrm{C}$.

\section{RESULTS AND DISCUSSION}

Aliphatic-aromatic copolyesters are formed by the high temperature melt reaction of post-consumer PET with poly(ethylene adipate) (PEA), even without added catalyst. The copolymers obtained can presents three different sequences structures represented by TET (terephthalate, ethylene, terephthalate), AEA (adipate, ethylene, adipate) and TEA (terephthalate, ethylene, adipate) in Figure 1.

The NMR analysis allowed us to observe the copolymer formation, the ${ }^{1} \mathrm{H}-\mathrm{NMR}$ spectra for PET, PEA and for a copolyester PET-co-PEA (50/50, wt \%) are shown in Figure 2 and the chemical shift and assignment of proton signal showed in ${ }^{1} \mathrm{H}$ NMR spectra are listed in Table 1.
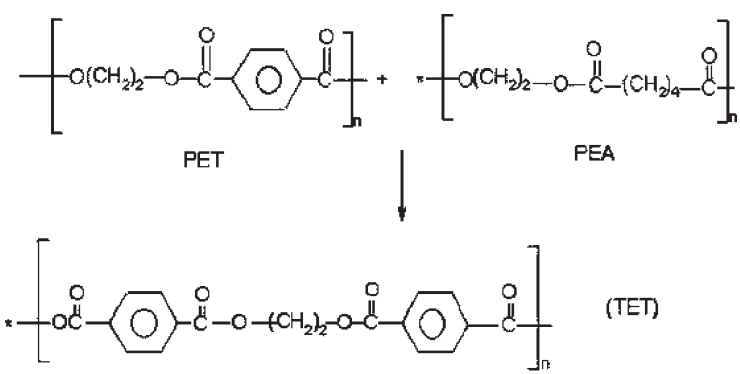

(TET)

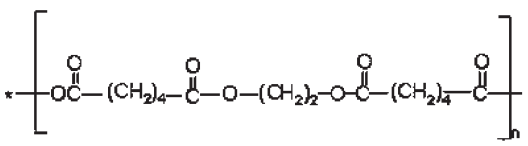

(AEA)

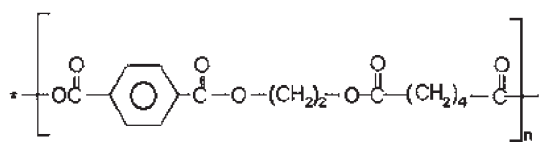

Figure 1. Possible sequences structures for the obtained copolyester

Table 1. Chemical shift and assignment of proton signal showed in ${ }^{1} \mathrm{H}$ NMR

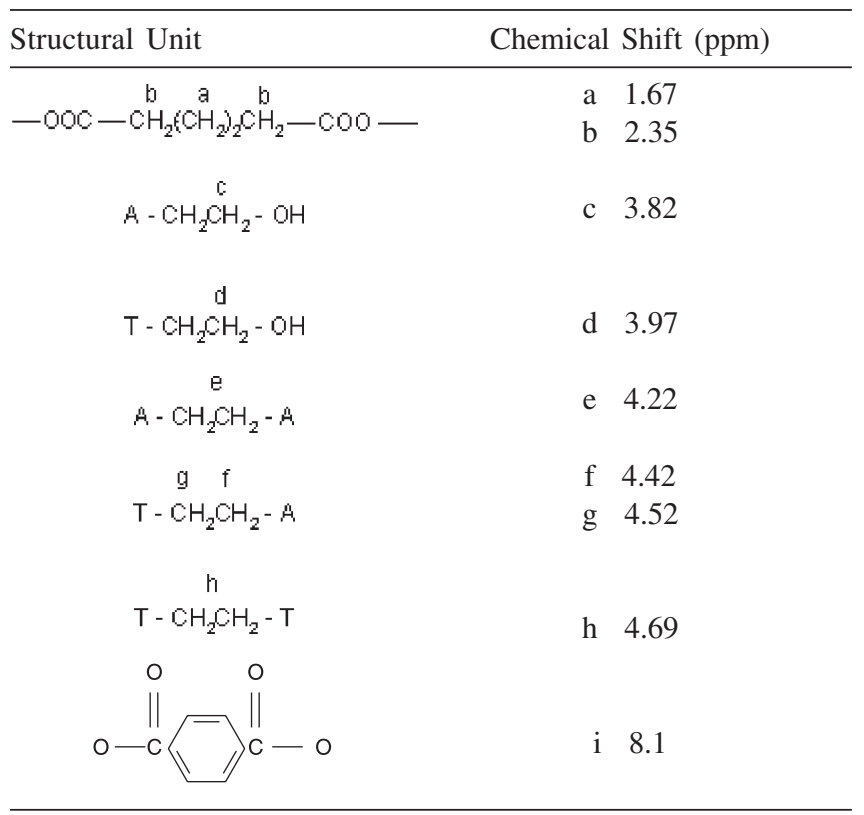

As we can see from Figure 2 and Table 1 spectra (a) show the typical peaks of PET, the peak centered in $8.16 \mathrm{ppm}$ can be assigned to benzene ring and the peak at $4.82 \mathrm{ppm}$ to the ethylenedioxyl group of PET. In the spectra (b) of PEA, we can see the peaks in $1.66 \mathrm{ppm}$ that belongs to $-\left(\mathrm{CH}_{2}\right)_{2}{ }^{-}$, and another peak in $2.35 \mathrm{ppm}$ that can be assigned to $-\mathrm{CH}_{2} \mathrm{COO}$ - in PEA units, in $4.26 \mathrm{ppm}$ we observe the ethylenedioxyl group of PEA. In the NMR spectra (c) of PET-co-PEA, except for the nuclear resonance characteristic of PET and PEA, we can see new peaks appearing in the range of 4$4.8 \mathrm{ppm}$. We attribute these peaks to the formation of new bonds for the sequences structures TEA showed in Figure 1. In $4.22 \mathrm{ppm}$ the peak is attributed to methylene protons of the ethylenedioxyl group in ET unit linking an adipate unit in AEA segment. The peak at $4.42 \mathrm{ppm}$ is the contribution of methylene protons of the ethylenedioxyl group in ET unit linking an adipate unit in TEA segment. The signal at $4.52 \mathrm{ppm}$ is assigned to methylene protons of the ET group in the TEA segments next to a terephthaloyl group. 

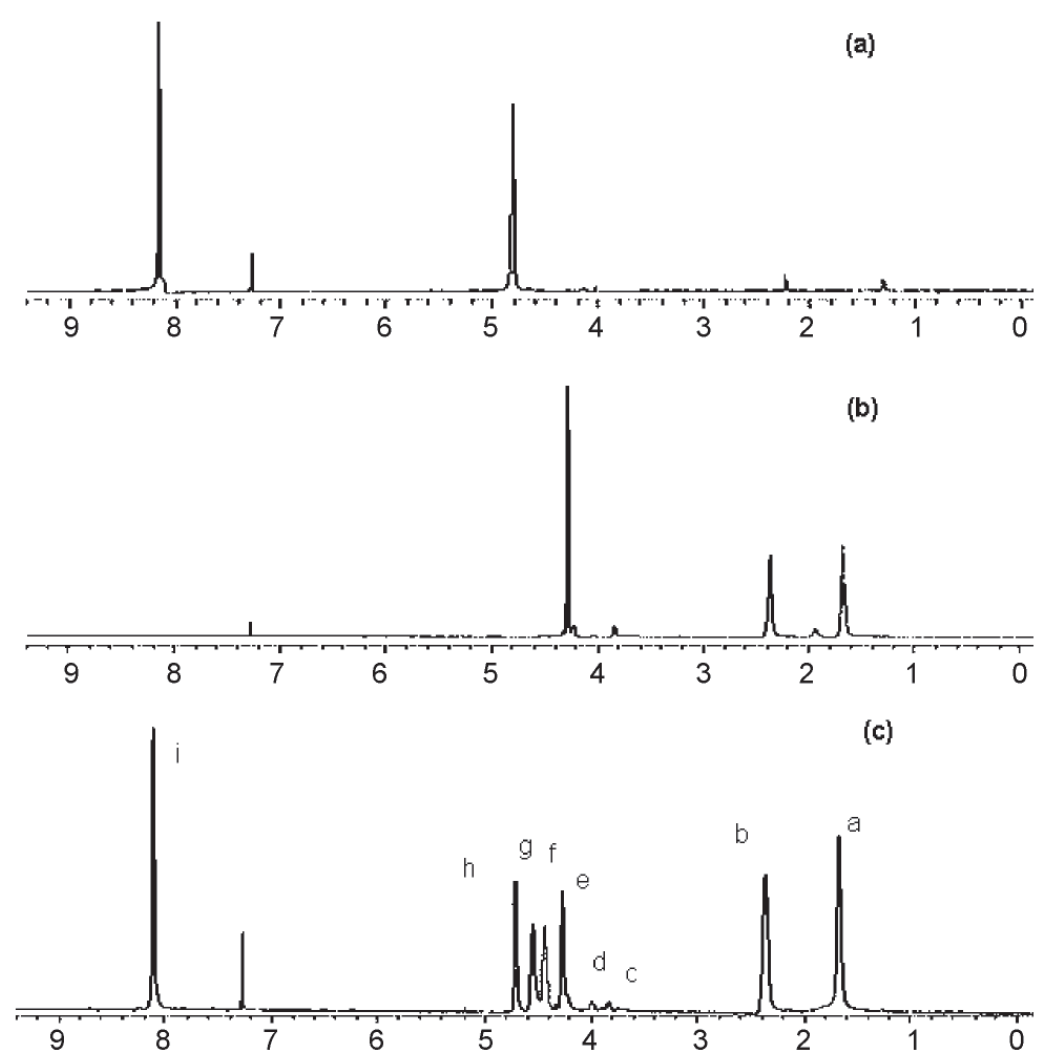

Figure 2. NMR spectra (a) PET, (b) PEA and (c) PET-co-PEA (50/50\% wt)

Finally, the peak at $4.69 \mathrm{ppm}$ is attributed to methylene units of TET segments. These attributions are in agreement with that for a copolymer PET-co-PEA $(90 / 10)^{6}$. We can also observe two signals one in 3.82 and another in 3.97 which are attributed to the resonances of the ethylene glycol group at the end of the chain as depicted from Figure 2 and Table 1.

In order to observe the evolution of copolymer formation with time and the behavior of intrinsic viscosity, we obtained samples of PET-co-PEA $(50 / 50 \% \mathrm{wt})$ at different reaction times (time in which the mixture was under vacuum), 0, 1, 3, 5, 10, 20, 40, 60 and $120 \mathrm{~min}$. The samples PET-co-PEA were obtained from the homopolymers PEA $([\eta]=0.0104 \mathrm{~mL} / \mathrm{mg})$ and PET post-consumer $([\eta]=0 ., 0736 \mathrm{~mL} / \mathrm{mg}$ ) in the conditions described in experimental section. The intrinsic viscosity of the copolymers was estimated and increases with reaction time until $20 \mathrm{~min}$, after that time we observe the degradation of copolymer assigned by both decrease in viscosity and the appearing of new peaks in the NMR spectra. Copolyesters PET-co-PEA obtained with addition of a catalyst during the synthesis resulted in a copolymer with higher viscosity than those obtained in the same reactions conditions but without the addition of catalyst. This behavior is due to simultaneous polycondensation and ester-interchange reactions in synthesis with the addition of a catalyst, instead in these reactions without addition of a catalyst we have only ester-interchange reactions. Table 2 summarizes the behavior of intrinsic viscosity with the reaction time and the influence of catalyst addition. For copolyester synthesis in times of 1 and 3 min we observed the signals in NMR spectra attributed to TEA segments formation of copolyester but the intrinsic viscosity obtained were very low.

As we can see from Table 2 the lowest values for intrinsic viscosity were obtained for the reaction without catalyst added and varied from $0.0101 \mathrm{~mL} / \mathrm{mg}$ (entry 1) for $5 \mathrm{~min}$ of reaction time to $0.0116 \mathrm{~mL} / \mathrm{mg}$ (entry 3 ) for $20 \mathrm{~min}$ of reaction time. For reactions
Table 2. Variation of the intrinsic viscosity [ $\eta$ ] of PET-co-PEA (50/50\% wt) with reaction time for reactions with and without catalyst added

\begin{tabular}{lccc}
\hline Entry & $\begin{array}{c}\text { Reaction } \\
\text { time } \\
\text { min }\end{array}$ & $\begin{array}{c}{[\eta]-\text { With }} \\
\text { catalyst added } \\
\text { mL/mg }\end{array}$ & $\begin{array}{c}{[\eta]-\text { Without }} \\
\text { catalyst added } \\
\mathrm{mL} / \mathrm{mg}\end{array}$ \\
\hline 1 & 5 & 0.0108 & 0.0101 \\
2 & 10 & 0.0117 & 0.0109 \\
3 & 20 & 0.0152 & 0.0116 \\
4 & 40 & 0.0132 & - \\
5 & 60 & 0.0133 & -
\end{tabular}

*Titanium butoxyde (IV); $245{ }^{\circ} \mathrm{C}$ under vacuum at desired time

with catalyst added we observe the same behavior, which means, the intrinsic viscosity increases with reaction time, the lowest obtained value is $0.0108 \mathrm{~mL} / \mathrm{mg}$ (entry 1) for $5 \mathrm{~min}$ of reaction time and the highest is 0.0152 for $20 \mathrm{~min}$ of reaction. For samples with catalyst addition, which had their viscosity evaluated, for reaction time equal or superior to $40 \mathrm{~min}$ we observed the polymer degradation and a decrease in intrinsic viscosity.

In utilizing the best reaction time, $20 \mathrm{~min}$, for samples PET-coPEA (50/50, wt $\%)$ we synthesized copolyesters with different ratio of PET/PEA with addition of catalyst in order to see the behavior of intrinsic viscosity and the polymer structure. The evaluation of intrinsic viscosity for samples with more than $50 \%$ in weight of PET content was difficult due to their partial solubilization in $\mathrm{CHCl}_{3}$, so for these compositions we will only presents the study by NMR of polymer structure that will be discussed later.

We have a strict relationship between biodegradability and terephthalic acid content. Biodegradability decreases with increase of PET content ${ }^{7,8,10}$. So, varying the terephthalic acid content, we are 
Table 3. Calculated molar ratio values from NMR spectra to samples (50,50 wt $\%)$ PET-co-PEA

\begin{tabular}{lcccccc}
\hline Entry & Reaction & \multicolumn{2}{c}{ TET segment } & \multicolumn{2}{c}{ AEA segment } & \multicolumn{2}{c}{ TEA segment } \\
time (min) & With cat. & Withou cat. & With cat. & Withou cat. & With cat. & Withou cat. \\
\hline 1 & 5 & 0.201 & 0.200 & 0.299 & 0.219 & 0.499 \\
2 & 10 & 0.192 & 0.195 & 0.313 & 0.321 & 0.501 \\
3 & 20 & 0.218 & 0.193 & 0.264 & 0.323 & 0.494 \\
4 & 40 & 0.219 & - & 0.253 & - & 0.517 \\
5 & 60 & 0.210 & 0.210 & 0.285 & 0.274 & 0.526 \\
\hline
\end{tabular}

Table 4. Calculated molar ratio values from NMR spectra to samples with different PET/PEA ratios

\begin{tabular}{lccc}
\hline Entry & PET/PEA wt, \% ratio & $\begin{array}{c}\text { Calculated value } \\
\text { TET/AEA/TEA }\end{array}$ & $\begin{array}{c}\text { Calculated value from NMR spectra } \\
\text { TET/AEA/TEA }\end{array}$ \\
\hline 7 & $60 / 40$ & $0.33 / 0.18 / 0.49$ & $0.36 / 0.16 / 0.47$ \\
8 & $70 / 30$ & $0.46 / 0.10 / 0.44$ & $0.47 / 0.09 / 0.43$ \\
9 & $75 / 25$ & $0.53 / 0.07 / 0.39$ & $0.62 / 0.06 / 0.31$ \\
10 & $80 / 20$ & $0.61 / 0.05 / 0.34$ & $0.76 / 0.07 / 0.18$ \\
\hline
\end{tabular}

altering mechanics and the biodegradability properties of copolyester. These changes allow us to adapt the obtained copolyester to desired applications, finding a compromise between biodegradability and mechanical properties. The biodegradability and hydrolysis behavior of the samples PET- co - PEA are being evaluated.

From the NMR spectra we can calculate the average block length of aromatic and aliphatic units, if we have block copolyesters, and the randomness of the copolyester if we have synthesized random copolyester.

If we have random copolyesters, the experimental molar ratio must be equal to their probability of existence calculated by statistics, so, theoretically, for the reaction of $1 \mathrm{~mol}$ of PET and $1 \mathrm{~mol}$ of PEA, the probability that the segments TET, AEA and AET occur are 25, 25 and $50 \%$ respectively. If we had block copolyester the probability would be $0.5 \%$ to the TET segment and $0.5 \%$ to the AEA segment.

The molecular weight for the repetition units of PET and PEA are 192.17 and $172.17 \mathrm{~g} / \mathrm{mol}$ respectively. For example, a copolymer PET/PEA (50/50 wt,\%) if we have a random copolymer, theoretically, the molar ratio of TET, AEA and AET occur are 0.25 , 0.25 and 0.50 respectively. If we had block copolyester the probability would be 0.50 to the TET segment and 0.50 to the AEA segment.

Using the integral values from NMR spectra to calculate these relations we can see that we have random copolyester for all ratios PET/PEA and all reaction times. Table 3 shows the experimental molar ratio for PET-co-PEA $(50 / 50 \mathrm{wt}, \%)$ calculated from integrals values from the NMR spectra for samples synthesized at different reaction time and with and without addition of a catalyst.

As we can see from Table 3 the experimental values calculated from NMR spectra allow us to state that even at reaction times of 5 min we have obtained a random copolyester in both cases, with and without catalyst addition (entry 1). For all reaction times we obtained experimental values near the theoretical values.

For the reactions with no additional catalyst added, it is important to emphasize, that we have an amount of residual catalyst from the copolymers PET and PEA, which must be active in the reaction of PEA and PET to form the copolymer.

Table 4 shows the calculated values for PET-co-PEA and those obtained experimentally through NMR spectra using the integral values to calculate the molar ratio for samples obtained at $20 \mathrm{~min}$ of reaction with catalyst addition and with different ratio of PET and PEA. The same behavior is observed for all PET and PEA contents, showing that we have random copolyester in all cases.

It's important to note that in all reaction we utilized PET postconsumer, showing that is possible by chemical recycling to obtain a new copolymer and aiding to solve the problems in the waste stream. The NMR spectra obtained for samples synthesized at different times were quite similar, allowing us to conclude that the reaction occurred even before 5 min of reaction.

\section{CONCLUSIONS}

We showed in this work that we can obtain new copolymers PET-co-PEA from the reaction of PET post-consumer with PEA by high temperature molten reaction. The reaction of PET and PEA in different ratios and reaction time produces the formation of random copolymer even at times smaller of 5 minutes as we could seen from NMR analysis.

\section{ACKNOWLEDGEMENTS}

Financial support from PUCRS, FAPERGS and CNPq is gratefully acknowledged. A. F. Baldissera and C. E. S. Valério thank FAPERGS for their fellowships.

\section{REFERENCES}

1. Parschal, W. G.; Ittel, S. D.; Homogeneous Catalysis, John Wiley \& Sons Inc: New York, 1992.

2. Kint, D.; Muñoz-Guerra, S.; Polym. Int. 1999, 48, 346.

3. Spychaj, T.; Paszun, D.; Macromol. Symp. 1998, 137.

4. Okada, M.; Okada, Y.; Tao A.; Aoi, K.; J. Appl. Polym. Sci. 1996, 2257.

5. Kint, D.; Deloret, E.; Campos, J.; Muñoz-Guerra, S.; Polymer 2003, 44, 1321.

6. Heidary, S.; Gordon III, B.; J. Environ. Polym. Degrad. 1994, 2, 19

7. Witt, U.; Müller, R. J.; Deckwer, W. D.; J. M. S. Pure Appl. Chem. 1995, 4,851 .

8. Witt, U.; Müller, R. J.; Deckwer, W. D.; J. Environ. Polym. Degrad. 1997, 5,81 .

9. Tokiwa, Y.; Suzuki, T.; J. Appl. Polym. Sci. 1981, 26, 441.

10. Witt, U.; Müller, R. J.; Deckwer, W. D.; Macromol. Chem. Phys. 1996, 197, 1525.

11. Fradet A., Tessier M. In Synthetic methods in Step-Growth Polymers; Rogers, M. E.; Long, T. E., eds.; Wiley-Interscience, 2003, chap. 2. 